American Journal of Applied Sciences 8 (11): 1101-1106, 2011

ISSN 1546-9239

(C) 2011 Science Publications

\title{
Dynamical Model for Determining Human Susceptibility to Dengue Fever
}

\author{
${ }^{1}$ Surapol Naowarat, ${ }^{1}$ Thanon Korkiatsakul and ${ }^{2}$ I. Ming Tang \\ ${ }^{1}$ Department of Mathematics, Faculty of Science and Technology, \\ Suratthani Rajabhat University, Surat Thani, 84100, Thailand \\ ${ }^{2}$ Department of Physics, Faculty of Science, Mahidol University, \\ Rama 6 Road, Bangkok, 10400, Thailand
}

\begin{abstract}
Problem statement: Mathematical models are a useful tool for understanding and describing the transmission of diseases such as dengue fever, one of the most prevalently emerging diseases common to tropical and subtropical areas throughout South East Asia. By taking into account human susceptibility to disease, the dynamics of a dengue disease model is proposed. Approach: Using standard methods for analyzing a system, the stability of the model is determined by using Routh-Hurwitz criteria. Results and Conclusion: We can show that the basic reproductive number $\left(\mathrm{R}_{0}\right)$, the threshold parameter, when $\mathrm{R}_{0}<1$, the disease-free state is locally asymptotically stable. If $\mathrm{R}_{0}$ $>1$, the endemic equilibrium state is locally asymptotically stable. Numerical results illustrate the dynamics of the disease within the context of varying parameter values.
\end{abstract}

Key words: Dengue Shock Syndrome (DSS), Dengue Haemorrhagic Fever (DHF), Dengue Fever (DF), mathematical model, female aedes mosquitoes, sequential infections

\section{INTRODUCTION}

Dengue fever is an infectious disease caused by the dengue virus (genus flavivirus, family Flaviviridae) (WHO, 2009). There are four closely related serotypes of this virus known as DEN-1, DEN-2, DEN-3 and DEN-4, all of which are transmitted to humans by the bite of infected female Aedes mosquitoes with Aedes aegypti being the principle vector and Aedes albopictus being a less common vector. Dengue fever occurs in tropical and subtropical regions around the world, predominantly in urban and semi-urban areas where mosquitoes can breed in water. Dengue fever has become a major international public health concern since it has been reported in over 100 countries and is estimated to affect more than one hundred million people each year (WHO, 2009) with infants and, unlike many diseases, well-nourished children being most at risk (Ranjit and Kissoon, 2010). For a yet-to-be explained reason, females are more susceptible to the disease than males (Guzman et al., 2010). It is estimated that 2.5 billion people live in dengue epidemic areas.

The spectrum of illness of dengue ranges from mild infection Dengue Fever (DF), to severe deadly disease Dengue Haemorrhagic Fever (DHF) and Dengue Shock Syndrome (DSS) (WHO, 2009). All of the four dengue viruses co-circulate in many areas of Africa, the Americas and Asia, the dominant serotype has changed irregularly (Chikaki and Ishikawa, 2009). Infection with one serotype confers permanent immunity against that serotype but only temporary and partial protection against the other three serotypes and secondary or sequential infections are possible after a short time (Rodenhuis-Zybert et al., 2010). A person infected with one DEN virus produces lifelong immunity against with that serotype but no long-term cross - protection against the other three serotypes but they may be re-infected by the other three serotypes in about three months and will concurrently become more susceptible to develop the more virulent DHF form of the disease (Gubler and Kuno, 1997).

Among many countries affected by the disease, all three forms of Dengue fever are endemic to Thailand. From 1997-2008, a total of 220,885 cases of DF, 650,810 cases of DHF and 17,268 cases of DSS were reported (Kongnuy et al., 2011). In many cases, the illness is asymptomatic and infection can only be determined through serologic tests. Sriprom et al. (2003) sought to classify the primary and the secondary infections of DHF in Thailand from 1998-2003. Serological tests established 1,082 confirmed cases divided into 214 due to primary infections, 291 due to

Corresponding Author: Surapol Naowarat, Department of Mathematics, Faculty of Science and Technology,

Suratthani Rajabhat University, Surat Thani, 84100, Thailand 
secondary infections and 577 undetermined. The predominant virus was DEN-1 (162), followed by DEN-2 (121), DEN-3 (70) and DEN-4 (17).

Multiple viruses were found in 3 patients. Halstead maintained that the mutation of the virus could have produced viruses with greater virulence and therefore greater epidemic potential.

Given the disease's widespread prevalence in Thailand, the need to better understand the epidemiology of Dengue fever is, therefore, most urgently needed. Simulation approaches using mathematical models have already proven themselves as important tools for understanding the spread and control of diseases as in the study of Adetunde (2009) and Koriko and Yusuf (2008) proposed mathematical models of Tuberculosis disease, determine the disease free and endemic equilibrium point and analyzed the stability. Naowarat et al. (2011) proposed and analyzed the mathematical model to control the transmission of Chikungunya Fever. Dengue models proposed by Estava and Vagus (1998) and by Yaacob (2007) may have even greater efficacy than those mentioned above as they permit both more than one serotype and the potential for re-infection to be incorporated within their models' parameters.

\section{MATERIALS AND METHODS}

Model formulation: In our model, we assume that human population and mosquito population are constant denoted by $\mathrm{N}_{\mathrm{H}}$ and $\mathrm{N}_{\mathrm{V}}$, respectively. The dynamics of the disease is depicted in the compartment diagram, as shown in Fig. 1.

The human population is partitioned into two compartments, the susceptible human $\left(\overline{\mathrm{S}}_{\mathrm{H}}\right)$ and the infected human $\left(\overline{\mathrm{H}}_{\mathrm{H}}\right)$ compartment.

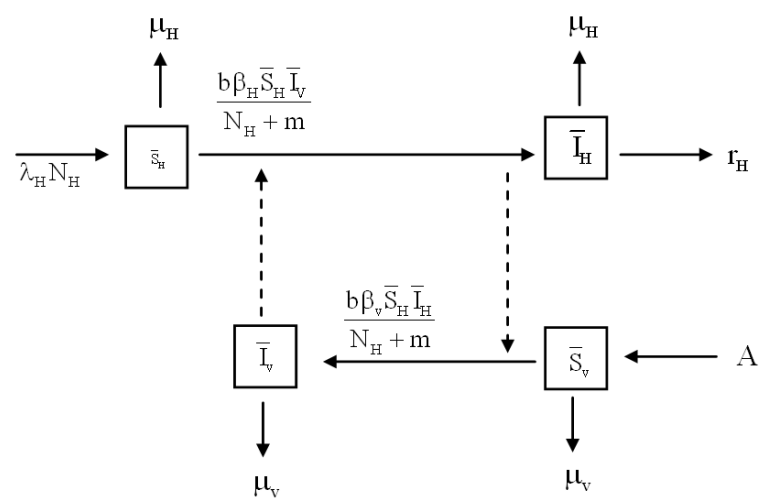

Fig. 1: Flow chart for the transmission of dengue disease
Since there is not enough information known about the degree of immunity conferred after recovery beyond what was mentioned earlier (i.e., only one serotype confers permanent immunity to itself but only temporary immunity to the other three), we assume that when a susceptible human is infected with one type of DEN virus they can be infected by the other types.

Likewise, for the purposes of this study we have omitted the recovered or immune human compartment. The mosquito population, in turn, is partitioned into two compartments.

The susceptible mosquito $\left(\overline{\mathrm{S}}_{\mathrm{v}}\right)$ and the infected mosquito $\left(\overline{\mathrm{I}}_{\mathrm{v}}\right)$ compartment. The recovered mosquito does not, of course, exist, as once infected as a carrier it will remain infected over the course of its two weeks life span.

The transmission dynamics of Dengue fever are described in the following differential equations, premised on the assumptions and exclusions outlined below Eq. 1:

$$
\begin{aligned}
\frac{d \bar{S}_{H}}{d t} & =\lambda_{H} N_{H}-\frac{b \beta_{H}}{N_{H}+m} \bar{S}_{H} \bar{I}_{\mathrm{V}}-\mu_{H} \bar{S}_{H}, \\
\frac{d \bar{I}_{H}}{d t} & =\frac{b \beta_{H}}{N_{H}+m} \bar{S}_{H} \bar{I}_{V}-\left(\mu_{H}+r_{H}\right) \bar{I}_{H}, \\
\frac{d \bar{S}_{\mathrm{V}}}{d t} & =A-\frac{b \beta_{V}}{N_{H}+m} \bar{S}_{\mathrm{V}} \bar{I}_{\mathrm{V}}-\mu_{\mathrm{V}} \bar{S}_{\mathrm{V}}, \\
\frac{d \overline{\mathrm{I}}_{\mathrm{V}}}{\mathrm{dt}} & =\frac{\mathrm{b} \beta_{\mathrm{V}}}{N_{\mathrm{H}}+\mathrm{m}} \overline{\mathrm{S}}_{\mathrm{V}} \overline{\mathrm{I}}_{\mathrm{V}}-\mu_{\mathrm{V}} \overline{\mathrm{I}}_{\mathrm{V}}
\end{aligned}
$$

With two conditions:

And:

$$
\mathrm{N}_{\mathrm{H}}=\overline{\mathrm{S}}_{\mathrm{H}}+\overline{\mathrm{I}}_{\mathrm{H}}
$$

$$
\mathrm{N}_{\mathrm{v}}=\overline{\mathrm{S}}_{\mathrm{v}}+\overline{\mathrm{I}}_{\mathrm{v}}
$$

The third equation can be canceled since the mosquito population is constant. i.e., $\overline{\mathrm{S}}_{\mathrm{v}}=\mathrm{N}_{\mathrm{v}}-\overline{\mathrm{I}}_{\mathrm{v}}$. The number of dependent variables is limited to three, designated as $\mathrm{S}_{\mathrm{H}}, \mathrm{I}_{\mathrm{H}}, \mathrm{I}_{\mathrm{V}}$.

To analyze the model we can normalize the Eq. 1 and define new variables:

$$
\begin{aligned}
& S_{H}=\frac{\bar{S}_{H}}{N_{H}}, I_{H}=\frac{\overline{\mathrm{I}}_{H}}{N_{H}}, \\
& S_{V}=\frac{\bar{S}_{V}}{N_{V}}=\frac{\bar{S}_{v}}{A /\left(\mu_{v}\right)} \text { and } I_{V}=\frac{\bar{I}_{v}}{N_{v}}=\frac{\bar{I}_{V}}{A /\left(\mu_{v}\right)}
\end{aligned}
$$

Since the total human and mosquito populations are constant, the time rate of change of the human 
population is equal to zero, i.e., $\frac{\mathrm{d} \overline{\mathrm{S}}_{\mathrm{H}}}{\mathrm{dt}}+\frac{\mathrm{d} \overline{\mathrm{I}}_{\mathrm{H}}}{\mathrm{dt}}=0$. This means that the birth rate and the death rate of the human population is equal; that is $\lambda \mathrm{H}=\mu \mathrm{H}$. The total number of mosquito at equilibrium is equal to $\frac{A}{\mu_{v}}$.

Where:

$$
\begin{aligned}
& \mathrm{S}_{\mathrm{H}},\left(\mathrm{I}_{\mathrm{H}}\right)=\text { The number of susceptible (infected) } \\
& \text { human population } \\
& \mathrm{S}_{\mathrm{v}},\left(\mathrm{I}_{\mathrm{v}}\right)=\text { The number of susceptible (infected) } \\
& \text { mosquito population } \\
& \lambda_{\mathrm{H}},\left(\mu_{\mathrm{H}}\right)=\text { The birth (death) rate of human population } \\
& \mathrm{A}=\text { The recruitment rate of mosquito } \\
& \text { population } \\
& \mathrm{m} \quad=\text { The number of other animals that the } \\
& \text { mosquitoes can feed on } \\
& \mathrm{N}_{\mathrm{H}},\left(\mathrm{N}_{\mathrm{v}}\right)=\text { The number of human(mosquito) } \\
& \text { population } \\
& \mathrm{b}\left(\mu_{\mathrm{v}}\right)=\text { The biting (death) rate of mosquito } \\
& \text { population } \\
& \gamma_{\mathrm{v}}=\text { The transmission rate of DEN virus from } \\
& \gamma_{\mathrm{v}}=\frac{\mathrm{Ab} \beta_{\mathrm{H}}}{\mu_{\mathrm{v}}\left(\mathrm{N}_{\mathrm{H}}+\mathrm{m}\right)}
\end{aligned}
$$

The reduced models are depicted as following Eq. 2:

$$
\begin{aligned}
\frac{d S_{H}}{d t} & =\mu_{H}\left(1-S_{H}\right)-\frac{A b \beta_{H}}{\mu_{v}\left(N_{H}+m\right)} S_{H} I_{v}, \\
\frac{d I_{H}}{d t} & =\frac{A b \beta_{H}}{\mu_{v}\left(N_{H}+m\right)} S_{H} I_{v}-\left(\mu_{H}+r_{H}\right) I_{H}, \\
\frac{d I_{v}}{d t} & =\frac{b \beta_{v} N_{H}}{N_{H}+m}\left(1-I_{v}\right) I_{H}-\mu_{v} I_{v}
\end{aligned}
$$

\section{Analysis of the model:}

Equilibrium points: The model will be analyzed to investigate the equilibrium points and its stability. The system has two possible equilibrium points: the disease free equilibrium point and an endemic equilibrium point. Two equilibrium points are found by setting the right hand side of Eq. 2 to zero we obtained.

Disease free equilibrium $\left(\mathbf{E}_{\mathbf{0}}\right)$ : In the absence of disease, that is $1_{\mathrm{H}}=0,1_{\mathrm{V}=} 0$. We obtained $\mathrm{S}_{\mathrm{H}}=1$, then the disease free equilibrium is $\mathrm{E}_{0}(1,0,0)$
Endemic equilibrium $\left(\mathbf{E}_{\mathbf{1}}\right)$ : In the other case when the disease is presented, $I_{H} \neq 0, I_{V} \neq 0$, we obtained Eq. 3:

$$
\begin{aligned}
S_{H}^{*} & =\frac{\beta+M}{\beta+M_{0}} \\
I_{H}^{*} & =\frac{R_{0}-1}{\beta+R_{0}} \\
I_{v}^{*} & =\frac{\beta\left(R_{0}-1\right)}{R_{0}(\beta+M)}
\end{aligned}
$$

Where:

$$
\beta=\frac{\mathrm{b} \beta_{\mathrm{v}} \mathrm{N}_{\mathrm{H}}}{\mu_{\mathrm{V}}\left(\mathrm{N}_{\mathrm{H}}+\mathrm{m}\right)}, \mathrm{M}=\frac{\mathrm{r}_{\mathrm{H}}+\mu_{\mathrm{H}}}{\mu_{\mathrm{H}}}
$$

And:

$$
\mathrm{R}_{0}=\frac{\mathrm{b}^{2} \beta_{\mathrm{H}} \beta_{\mathrm{v}} \mathrm{N}_{\mathrm{H}} \mathrm{A} /\left(\mu_{\mathrm{v}}\right)}{\left(\mathrm{N}_{\mathrm{H}}+\mathrm{m}\right)^{2} \mu_{\mathrm{v}}\left(\mathrm{r}_{\mathrm{H}}+\mu_{\mathrm{H}}\right)}
$$

Then the endemic equilibrium point is $\mathrm{E}_{1}\left(\mathrm{~S} *_{\mathrm{H}}, 1 *_{\mathrm{H}}, 1 *_{\mathrm{v}}\right)$.

Local asymptotical stability: The local stability of an equilibrium point is determined from the Jacobian matrix of the system of ordinary differential Eq. 2 evaluated at each equilibrium point. The Jacobian matrix at $\mathrm{E}_{0}$ is shown as Eq. 4:

$$
J_{0}=\left[\begin{array}{ccc}
-\mu_{\mathrm{H}} & 0 & \frac{-\mathrm{Ab} \beta_{\mathrm{H}}}{\mu_{\mathrm{v}}\left(\mathrm{N}_{\mathrm{H}}+\mathrm{m}\right)} \\
0 & -\left(\mu_{\mathrm{H}}+\mathrm{r}_{\mathrm{H}}\right) & \frac{\mathrm{Ab} \beta_{\mathrm{H}}}{\mu_{\mathrm{v}}\left(\mathrm{N}_{\mathrm{H}}+\mathrm{m}\right)} \\
0 & \frac{\mathrm{b} \beta_{\mathrm{v}} \mathrm{N}_{\mathrm{H}}}{\mathrm{N}_{\mathrm{H}}+\mathrm{m}} & -\mu_{\mathrm{v}}
\end{array}\right]
$$

The eigenvalues of the $\mathrm{J}_{0}$ are obtained by solving det $\quad\left(\mathrm{J}_{0}-\lambda \mathrm{I}\right)=0$. We obtained the following characteristic Eq. 5, we get $\lambda_{1}=-\mu_{\mathrm{H}}$

And:

$\lambda^{2}+\left(\mu_{\mathrm{H}}+\mathrm{r}_{\mathrm{H}}+\mu_{\mathrm{v}}\right) \lambda+\mu_{\mathrm{v}}\left(\mu_{\mathrm{H}}+\mathrm{r}_{\mathrm{H}}\right)\left(1-\mathrm{R}_{0}\right)=0$

We obtain:

$$
\lambda_{2}=\frac{-\left(\mu_{H}+r_{H}+\mu_{v}\right)-\sqrt{\left(\mu_{H}+r_{H}+\mu_{v}\right)^{2}-4 \mu_{v}\left(\mu_{H}+r_{H}\right)\left(1-R_{0}\right)}}{2}
$$

And:

$\lambda_{3}=\frac{-\left(\mu_{\mathrm{H}}+\mathrm{r}_{\mathrm{H}}+\mu_{\mathrm{v}}\right)+\sqrt{\left(\mu_{\mathrm{H}}+\mathrm{r}_{\mathrm{H}}+\mu_{\mathrm{v}}\right)^{2}-4 \mu_{\mathrm{v}}\left(\mu_{\mathrm{H}}+\mathrm{r}_{\mathrm{H}}\right)\left(1-\mathrm{R}_{0}\right)}}{2}$ 
Which the last two eigenvalues is negative if $\mathrm{R}_{0}<1$.

Disease endemic equilibrium: To determine the stability of the endemic equilibrium point, $\mathrm{E}_{1}$, by finding the eigenvalues of Jacobian matrix at $\mathrm{E}_{1}$, as follow Eq. 6:

$$
J_{1}=\left[\begin{array}{ccc}
-\mu_{\mathrm{H}}\left(\frac{\beta+\mathrm{MR}_{0}}{\beta+\mathrm{M}}\right) & 0 & -\frac{\mu_{\mathrm{H}} \mathrm{MR}_{0}}{\beta}\left(\frac{\beta+\mathrm{M}}{\beta+\mathrm{MR}_{0}}\right) \\
\frac{\mu_{\mathrm{H}} \mathrm{M}\left(\mathrm{R}_{0}-1\right)}{\beta+\mathrm{M}} & -\mu_{\mathrm{H}} \mathrm{M} & \frac{\mu_{\mathrm{H}} \mathrm{MR}_{0}}{\beta}\left(\frac{\beta+\mathrm{M}}{\beta+\mathrm{MR}_{0}}\right) \\
0 & \frac{\mu_{\mathrm{v}} \beta}{\mathrm{R}_{0}}\left(\frac{\beta+\mathrm{MR}_{0}}{\beta+\mathrm{M}}\right) & -\mu_{\mathrm{v}} \mathrm{R}_{0}\left(\frac{\beta+\mathrm{M}}{\beta+\mathrm{MR}_{0}}\right)
\end{array}\right]
$$

The characteristic Eq. 7 is calculated by setting det $\left(\mathrm{J}_{1}-\lambda 1\right)=0$. We obtain:

$\lambda^{3}+\mathrm{A} \lambda^{3}+\mathrm{B} \lambda+\mathrm{C}=0$

Where:

$$
\begin{aligned}
& \mathrm{A}=\frac{\mu_{\mathrm{H}}\left(\beta+\mathrm{MR}_{0}\right)}{\beta+\mathrm{M}}+\mu_{\mathrm{v}} \mathrm{M}+\frac{\mu_{\mathrm{v}} \mathrm{R}_{0}(\beta+\mathrm{M})}{\beta+\mathrm{MR}_{0}} \\
& \mathrm{~B}=\frac{\mu_{\mathrm{H}}^{2} \mathrm{M}\left(\beta+\mathrm{MR}_{0}\right)}{\beta+\mathrm{M}}+\mu_{\mathrm{v}} \mu_{\mathrm{H}} \mathrm{R}_{0}+\frac{\mu_{\mathrm{v}} \mu_{\mathrm{H}} \mathrm{M} \beta\left(\mathrm{R}_{0}-1\right)}{\beta+\mathrm{MR}_{0}}
\end{aligned}
$$

And:

$$
\mathrm{C}=\mu_{v} \mu_{\mathrm{H}}^{2} \mathrm{M}\left(\mathrm{R}_{0}-1\right)
$$

By using Routh-Hurwitz criteria, the endemic equilibrium point is locally stable if the following conditions are satisfied:

1. $\mathrm{A}>0$

2. $\mathrm{C}>0$

3. $\mathrm{AB}>\mathrm{C}$

It can be easily seen that $\mathrm{A}>0, \mathrm{C}>0$ with $\mathrm{R}_{0}>1$. Consider:

$$
\begin{aligned}
& \mathrm{AB}=\left(\frac{\mu_{\mathrm{H}}\left(\beta+\mathrm{MR}_{0}\right)}{\beta+\mathrm{M}}+\mu_{\mathrm{H}} \mathrm{M}+\frac{\mu_{\mathrm{v}} \mathrm{R}_{0}(\beta+\mathrm{M})}{\beta+\mathrm{MR}_{0}}\right) \\
& \left(\frac{\mu_{\mathrm{H}}^{2} \mathrm{M}\left(\beta+\mathrm{MR}_{0}\right)}{\beta+\mathrm{M}}+\mu_{\mathrm{v}} \mu_{\mathrm{H}} \mathrm{R}_{0}+\frac{\mu_{\mathrm{v}} \mu_{\mathrm{H}} \mathrm{M} \beta\left(\mathrm{R}_{0}-1\right)}{\beta+\mathrm{MR}_{0}}\right) \\
& \mathrm{AB}>\mu_{\mathrm{v}} \mu_{\mathrm{H}}^{2} \mathrm{MR}_{0}>\mathrm{C}
\end{aligned}
$$

Thus $E_{1}$ is locally asymptotically stable.

\section{RESULTS}

The system of Eq. 2 was solved numerically using the values of the parameters are given in Table 1 .
Table 1: Parameter values leading to disease-free state

\begin{tabular}{lc}
\hline Parameters & Value \\
\hline $\mathrm{A}$ & 400.0000 \\
$\mathrm{~b}$ & $0.5000 \mathrm{day}^{-1}$ \\
$\mu_{\mathrm{V}}$ & $0.2500 \mathrm{day}^{-1}$ \\
$\mu_{\mathrm{H}}$ & $1 /(60 \times 365) \mathrm{day}^{-1}$ \\
$\mathrm{~m}$ & 0.0000 \\
$\mathrm{r}_{\mathrm{H}}$ & $0.1428 \mathrm{day}^{-1}$ \\
$\beta_{\mathrm{H}}$ & 0.7500 \\
$\beta_{\mathrm{V}}$ & 1.0000 \\
$\mathrm{~N}_{\mathrm{H}}$ & 10000.0000 \\
\hline
\end{tabular}

Stability of disease-free state: From the values of the parameters listed in Table 1, the calculated eigenvalues and basic reproductive number are: $\lambda_{1}=-0.0000457, \lambda_{2}$ $=-0.377725, \lambda_{2}=-0.0151206$ and $R_{0}=0.840067$. Since these values leads to all of the eigenvalues to be negative and the basic reproductive number to be less than one, the equilibrium state will be the disease - free state, $\mathrm{E}_{0}$ as shown in Fig. 2.

Stability of endemic state: Next we change the value of the recruitment rate of mosquito (A ) from 400 to be equal to 5000 and keep the other values of the parameters the same. With these values, we obtain: $\lambda_{1^{-}}$ 0.0000619503. $\lambda_{2}=-0.125327-0.484337 \mathrm{i}, \lambda_{3}=-$ $0.125327+0.484337 \mathrm{i}$ and $\mathrm{R}_{0}=10.0008>1$. This along the fact that the real parts of the eigenvalues are all negative leads to the eqilibrium state to be the endemic state, $E_{1}$ and this state will be locally asymptotically stable. The fact that $\lambda_{2}$ and $\lambda_{3}$ are complex conjugates means that the tempolary behavior of the population will exhibit oscillatory behaviors. The time series solutions for susceptible human, infected human and infected mosquito as shown in Fig. 3. Furthermore, in Fig. $4 \mathrm{a}$ and $\mathrm{b}$, the trajectories of the solutions in the $\left(\mathrm{S}_{\mathrm{H}}, 1_{\mathrm{V}}\right)$ plane and $\left(1_{\mathrm{H}}, 1_{\mathrm{V}}\right)$ plane, respectively the trajactories spiraling into the equilibrium endemic state; Fig. 4c It shown that the infected human with restpect to $R_{0}$, as $I_{H}^{*}=0$ where $R_{0}<1$, the disease freeequilibrium is stable; If $R_{0}>1$ the endemic equilibrium is stable the solution $I_{\mathrm{H}}^{*}>0$, which approach to the endemic state.

\section{DISCUSSION}

We establish the threshold parameter for this model is:

$$
\mathrm{R}_{0}=\frac{\mathrm{b}^{2} \beta_{\mathrm{H}} \beta_{\mathrm{v}} \mathrm{N}_{\mathrm{H}} \mathrm{A} /\left(\mu_{\mathrm{v}}\right)}{\left(\mathrm{N}_{\mathrm{H}}+\mathrm{m}\right)^{2} \mu_{\mathrm{v}}\left(\gamma_{\mathrm{H}}+\mu_{\mathrm{H}}\right)}
$$

The quantity $\tilde{R}_{0}=\sqrt{R_{0}}$ is the basic reproductive number of the disease. It represents the average number of secondary cases that one case can produce if introduced into a sesceptible population (Anderson and May,1992). 


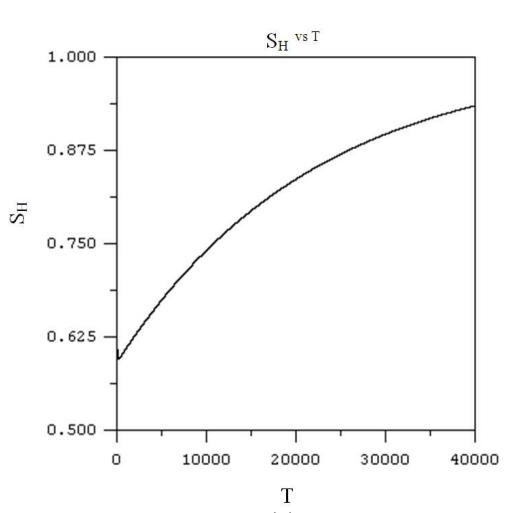

(a)

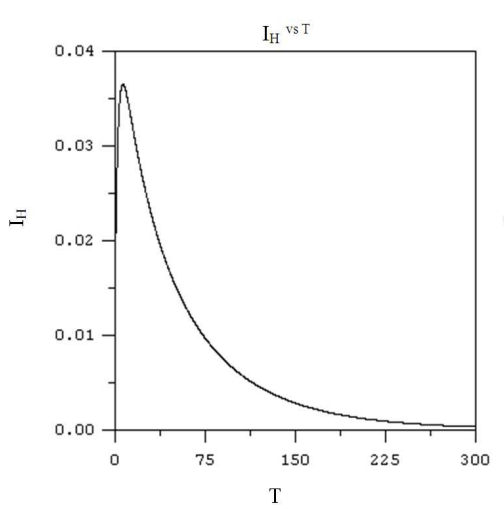

(b)

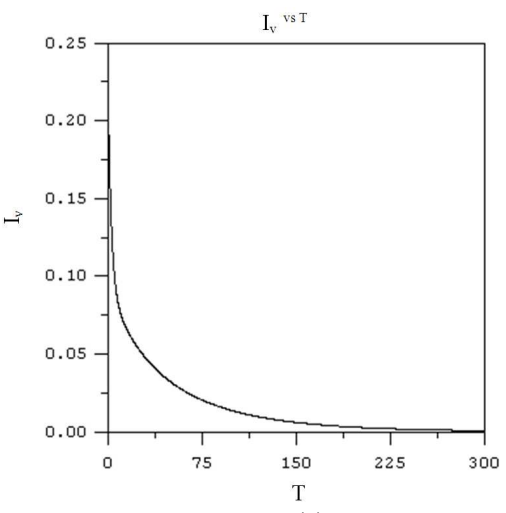

(c)

Fig. 2: Numerical solution of system (2), time series of (a) $S_{H}$, (b) $I_{H}$ and (c) $I_{V}$ with $A=400, b=0.5, \mu_{V}=0.25$, $\mu_{\mathrm{H}}=1 /(60 \times 365), \mathrm{r}_{\mathrm{H}}=0.1428, \beta_{\mathrm{H}}=0.75, \beta_{\mathrm{V}}=1.0, \mathrm{~N}_{\mathrm{H}}=10000$, eigenvalues are $\lambda_{1}=-0.0000457, \lambda_{2}=-0.377725, \lambda_{3}=-$ 0.0151206 and $\mathrm{R}_{0}-0.840067<1$. The numerical solutions converge to the disease - free state $\mathrm{E}_{0}(1,0,0)$

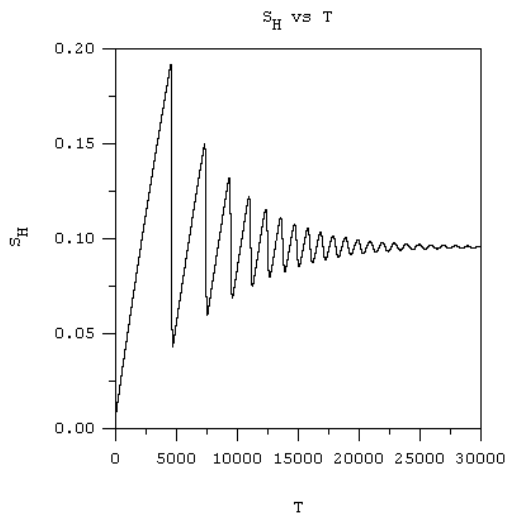

(a)

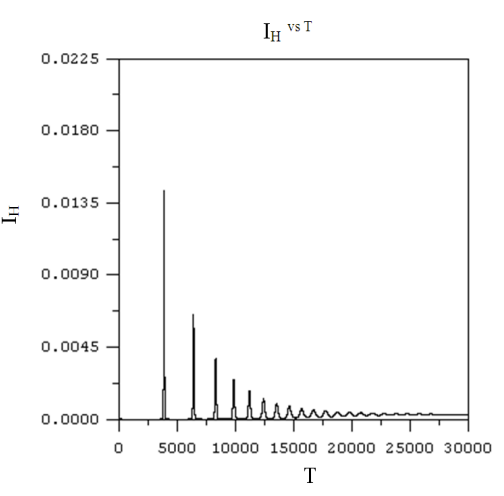

(b)

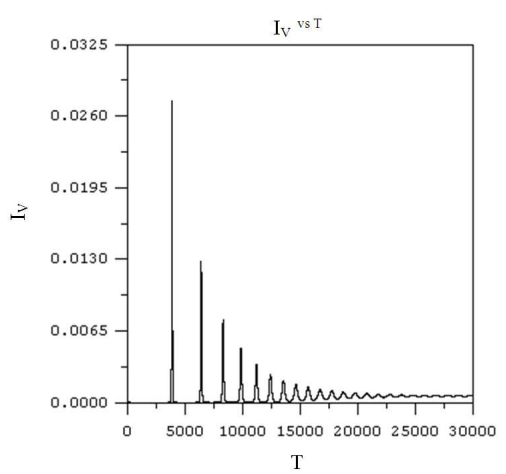

(c)

Fig. 3: Numerical solution of system (2), time series of (a) $S_{H}$, (b) $I_{H}$ and (c) $I_{V}$ with $A=5000, b=0.5, \mu_{V}=0.25$, $\mu_{\mathrm{H}}=1 /(60 \times 365), \mathrm{r}_{\mathrm{H}}=0.1428, \beta_{\mathrm{H}}=0.75, \beta_{\mathrm{v}}=1.0, \mathrm{~N}_{\mathrm{H}}=10000$, eigenvalues are $\lambda_{1}=-0.000619503, \lambda_{2}=-0.125327$ $0.484337 \mathrm{i}, \lambda_{3}=-0.125327+0.484337 \mathrm{i}$ andR $\mathrm{R}_{0}=10.0008>1$

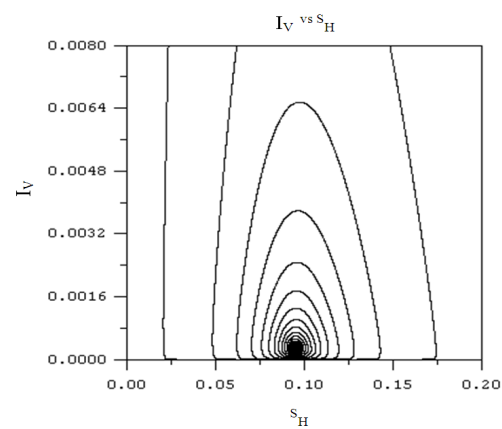

(a)

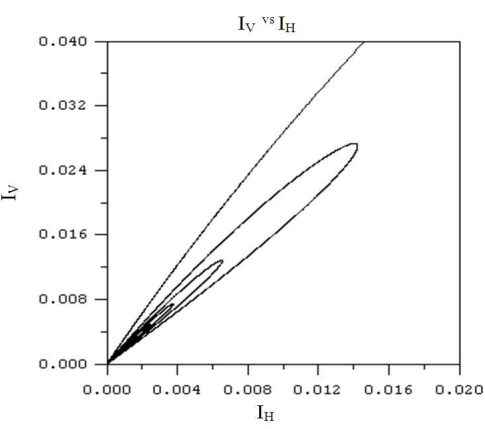

(b)

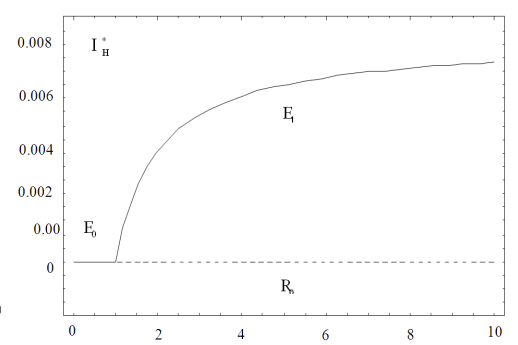

(c)

Fig. 4: Trajectories of human - mosquito population of system

The numerical solutions converge to the endemic state $\mathrm{E}_{1}(0.0952856,0.000289441,0.000578548)$.
Our simulation results show that the basic reproductive number will be increase if the recruitment 
rate of mosquito is increase. i.e., we find that $R_{0}=$ 2.100168 for the recruitment rate of mosquito $\mathrm{A}=1000$ and $\mathrm{R}_{0}=14.701177$ for $\mathrm{A}=7000$. The normalized individual populations are shown when the values of the basic reproductive number are different, as shown in the Fig. 2 and 3. Here we can see that the normalized individaul populations converge to the disease- free equilibrium point for $\mathrm{R}_{0}<1$. In cases of $\mathrm{R}_{0}>1$, the normalized individual populations oscillate to the endemic equilibrium point. The basic reproductive numbers are used for controlling the disease (Pongsumpun and Tang, 2008) and (Pongsumpun, 2010) by decreasing the carry capacity of the environment for mosquitoes by frequent reduction of mosquito breeding sites, seems to be a more efficative way of controlling the disease:

- (2), in the $(\mathrm{a})\left(\mathrm{S}_{\mathrm{H}}, \mathrm{I}_{\mathrm{H}}\right)$ and (b) $\left(\mathrm{I}_{\mathrm{H}}, \mathrm{I}_{\mathrm{V}}\right)$ plane, the solution approach to the endemic state; (c)

- Bifurcation diagram for equilibrium of system (2), demonstrate the infected human with restpect to $\mathrm{R}_{0}$, represents the stable solutions and represents the unstable solutions for $\mathrm{R}_{0}<1, \mathrm{E}_{0}$ will be stable, $\mathrm{R}_{0}>1, \mathrm{E}_{1}$ will be stable, with the same set of parameters used in Fig. 3

\section{CONCLUSION}

In this study, we have proposed and analyzed the dynamical transmission of Dengue fever by taking into account the role played without immunity in human population. We found that there are two equilibrium states, a disease-free state and endemic state. This will decrease the basic reproductive number to below one. Consequently, we can reduce the human sucecptibility to the disease and, in turn, this can reduce the outbreak of the disease.

\section{ACKNOWLEDGMENT}

Surapol Naowarat would like to thank Assoc. Prof. Dr. Thongchai Kruahong, Asst. Prof. Dr. Duangrut Patamaraka for giving me suggestions, Asst. Prof. Dr. Narong Buddhichiwin and Suratthani Rajabhat University for financial support according to Code: 2552 A1590213

\section{REFERENCES}

Adetunde, I.A., 2009. The mathematical models of the dynamical behavior of tuberculosis disease in the upper East region of the Northern Part of Ghana: A case study of bawku. Curr. Res. Tuberculosis., 1: 1-6.

Anderson, R.M. and R.M. May., 1992. Infectious Diseases of Humans: Dynamics and Control. 1st Edn., Oxford University Press, Oxford, ISBN: 019854040X, pp: 768.
Chikaki, E. and H. Ishikawa, 2009. A dengue transmission model in Thailand considering sequential infections with all four serotypes. J. Infect. Dev. Ctries., 3: 711-722. PMID: 19858573

Estava, L. and C. Vasgus, 1998. Analysis of a dengue disease transmission model. Math. Biosci., 150: 131-151. DOI: 10.1016/S0025-5564(98)10003-2

Guzman, M.G., S.B. Halstead, H. Artsob, P. Buchy and J. Farrar et al., 2010. Dengue: A continuing global threat. Nat. Rev. Microbiol., 8: S7-S16. PMID: 21079655

Kongnuy, R., E. Naowanich and P. Pongsumpun, 2011. Analysis of a dengue disease transmission model with clinical diagnosis in Thailand. Int. J. Math. Models Methods Applied Sci., 5: 594-601.

Koriko, O.K. and T.T. Yusuf, 2008. Mathematical model to simulate tuberculosis disease population dynamics. Am. J. Applied. Sci., 5: 301-306. DOI: 10.3844/ajassp.2008.301.306

Naowarat, S., W. Tawarat and I.M. Tang, 2011. Control of the transmission of Chikungunya fever epidemic through the use of adulticide. Am. J. Applied. Sci., 8: 558-565. DOI: 10.3844/ajassp.2011.558.565

Pongsumpun, P. and I.M. Tang, 2008. Effect of the seasonal variation in the extrinsic incubation peroid on the long term behavior of the dengue hemorrhagic fever epidemic. World Acad. Sci. Eng. Technol., 34: 377-383.

Pongsumpun, P., 2010. Dynamical transmission model of chikungunya in Thailand. World Acad. Sci. Eng. Technol., 68: 1161-1165.

Ranjit, S. and N. Kissoon, 2010. Dengue hemorrhagic fever and shock syndromes. Pediatr. Crit. Care. Med., 12: 90-100. PMID: 20639791

Rodenhuis-Zybert, I.A., J. Wilschut and J.M. Smith, 2010. Dengue virus life cycle: viral and host factors modulating infectivity. Cell. Mol. Life. Sci., 67: 2773-2786. DOI: 10.1007/s00018-010-0357-z

Sriprom, M., P. Pongsumpan, S. Yoksan, P. Barbazan and J.P. Gonzalez et al., 2003. Dengue haemorrhagic fever in Thailand, 1998-2003: Primary or secondary infection. Dengue. Bull., 27: 39-45.

Gubler, D.J. and G. Kuno, 1997. Dengue Fever and Dengue Hemorrhagic Fever. 1st Edn., CAB International, Wallingford ISBN-10: 0851991343, pp: 478.

WHO, 2009. Dengue: Guidelines for Diagnosis, Treatment, Prevention and Control. 1st Edn., World Health Organization, Geneva, ISBN: 9241547871, pp: 147.

Yaacob, Y., 2007. Analysis of a dengue disease transmission model without immunity. Matematika, 23: 75-81. 